\title{
Gold standard approach for removing sialoliths from the submandibular gland
}

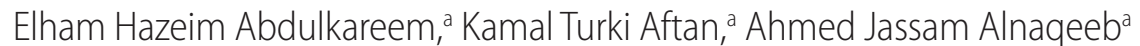

${ }^{a}$ Oral and Maxillofacial Surgery Department, College of Dentistry, University of Anbar, Iraq

Correspondence to Elham Hazeim Abdulkareem (email: den.elham.h@uoanbar.edu.iq).

(Submitted: 19 October 2017 - Revised version received: 07 November 2017 - Accepted: 14 January 2018 - Published online: 26 March 2018)

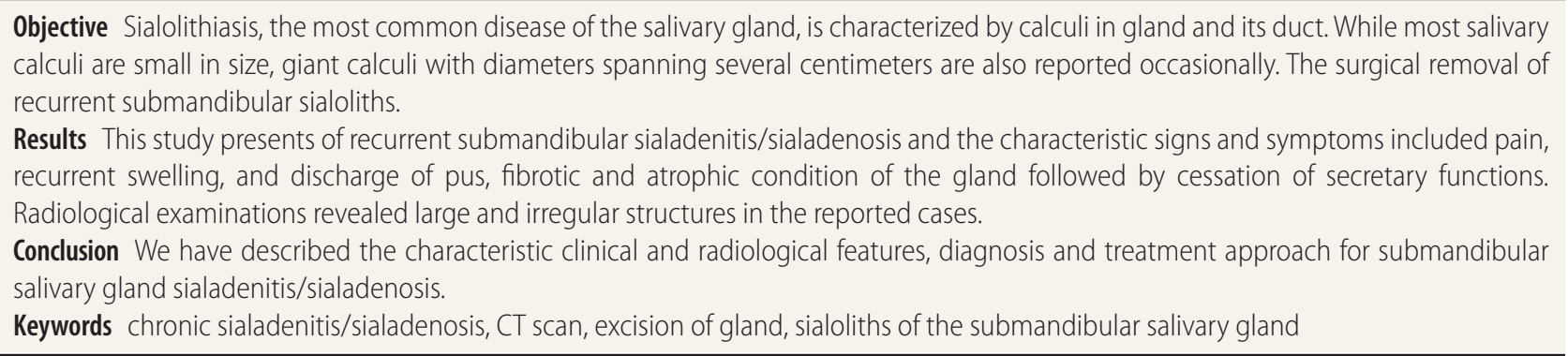

\section{Introduction}

Sialadenosis is one of the predominantly occurring conditions of the salivary glands. ${ }^{1-3}$ Carbonate and phosphate forms of calcium, remains of desquamated epithelia of salivary gland, mucopolysaccharides and glycoprotein like organic components constitute a sialolith, though bacterial activity is unidentified in the existing literature. ${ }^{4-6}$ Based on the majority of reported cases, it is estimated that out of 1,000 adults, 12 are afflicted with sialolithiasis annually and majority of them constitute male population.?

The frequency of rapidly setting (acute) and persistent (chronic) infections of sialolithiasis affecting submandibular salivary gland is higher by $90 \%$ while parotid gland affliction is $6 \%$, remaining $2 \%$ affects sublingual gland but minor saliva secretion glands seldom develop calculi. The dimension of the stone ranges between scant centimeters and $1 \mathrm{~mm}$, majorly less than $10 \mathrm{~mm} .^{8}$ Also, only very few cases have noted giant calculi with the diameter exceeding $15 \mathrm{~mm} .^{9}$ The causative factors constitute stand still flow of the saliva in the mouth, diameter and extent of the ducts, course of salivary rush and its composition, extreme basic nature, presence of infectious organisms in the mouth or substantial injury to the gland or the ducts. ${ }^{10}$ Due to high levels of calcium, phosphate, mucus and greater basicity, the sequential genesis of stones armor in submandibular gland as compared to any other salivary gland. When the components of stone separate out on the basis of their solubility, the calculus happens to be the primary hydroxyapatite cynosure ${ }^{11}$ Sialoliths are believed to be born in the ducts, which facilitates the stones to have an elaborate dimension and be submerged in saliva. Calculi might take long duration to enhance their dimensions and in the meanwhile do not display any signs or symptoms. ${ }^{12}$ Other potential reasons for calculus developing majorly in submandibular gland could be attributed to increased length and duct diameter, anti-gravitational course, lesser glide of the saliva, increased basicity, mucous and the concentration of calcium. ${ }^{13}$

The most noticeable feature includes infective condition of the related gland in addition to the repeated discomfort in neck and mouth. ${ }^{14}$ Absolute closure gives continuous pain due to swelling and pus discharge while prolonged closure leads to glandular atrophy and fibrosis followed by cessation of saliva ejection. If the calculus is placed posteriorly, it can be felt by palpating the floor of the oral cavity. ${ }^{15} \mathrm{~A}$ careful palpation of the oral floor allows the detection of the exact position of a stone and the diagnosis can be confirmed through ultrasonography (USG), conventional radiography, computed tomography (CT), and/or cone beam computed tomography. ${ }^{16} \mathrm{~A}$ CT scan gives exact dimension of the submandibular gland calculus and helps to select the treatment modality. ${ }^{17} \mathrm{CT}$ is the most meticulous method to locate the position of the stones. ${ }^{18}$

Many surgical techniques are performed to treat the submandibular gland sialadenosis. The initial method used involves putting an incision in the oral cavity on the mucosal lining over the stone so that it is easily removed. ${ }^{19}$

Chronic sialadenitis is a severe condition that leads to salivary gland hypofunction. Prolonged barrier in the ductal system leads to infectious disorders and inflamed tissues; therefore, it should be excised. ${ }^{20}$ The following case report presents the condition of three patients with prolonged ductal obstruction, atrophy and fibrosis followed by loss of saliva secretion. ${ }^{21}$ The aim of this study is the surgical removal of recurrent large submandibular sialoths.

\section{Materials and Methods}

\section{Patients}

The present study was reported at the Al Ramadi Teaching Hospital, Ramadi, Iraq. A total of 30 patients were admitted in the Maxillofacial Department with an ailment of swelling, pain and inflammation on one side restricted to the lower jaw region. Written consent for publication of their cases and images has been obtained from the respective patients. Committee of Ethics of Al-Ramadi Teaching Hospital has assented to this study (Registration number: 1694 on 06/08/2017) and 

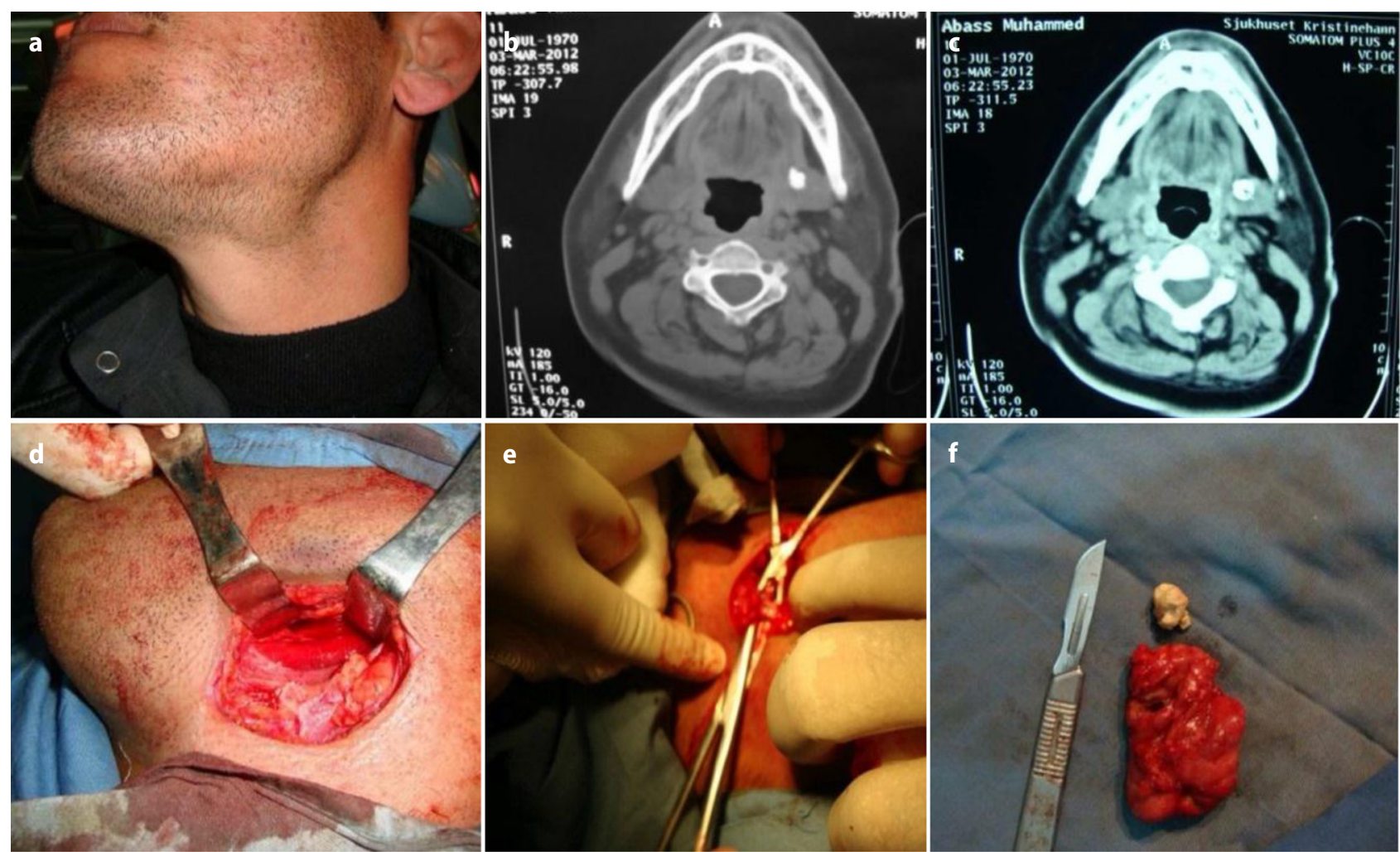

Fig 1. (a) Clinical examination revealed left submandibular swelling and tenderness, with a large salivary calculus palpable on the left floor of the mouth. (b and c) The presence of the sialolith was confirmed on CT, with an opaque mass evident in the left submandibular region. $(d-f)$ The patient underwent excision of the submandibular gland and stone via the standard extra-oral approach, without any complications.

Committee of Ethics of University of Anbar has assented to this study (Registration number: 38 on 19/12/2017).

Patient A: A 47-years-old male with above-mentioned symptoms on the left side of the mandible was observed (Fig. 1a). He had tender pain, fever and chills. Palpation (bimanual) inside the mouth reflected swelling while pressure on the ductal orifice, revealed pus discharge. CT image showed calcified structure in the left submandibular gland that confirmed the primary diagnosis of sialolithiasis (Fig. 1b, c).

Patient B: A 77-years-old female with aforementioned symptoms on the right side of the mouth floor having a large palpable stone was observed. On CT scan image, an opaque mass made the sialolithiasis diagnosis evident (Fig. 2).

Patient C: A 55-years-old non-smoker female with symptoms similar to the other two patients, but the stone was observed in the left submandibular gland and beneath the tongue. Palpable mass was mobile, soft and presents sensation of a nut below the tongue (left side). CT scan demonstrated radiopaque lesion reinforcing the diagnosis as sialolithiasis (Fig 3).

\section{Surgical Treatments}

We elected to surgically remove sialolith along with the gland under general anesthesia. Submandibulectomy and sialadenectomy were performed by an incision through the dermal layers, between two locations; exactly $2 \mathrm{~cm}$ beneath the mandibular lower border and above the gland. Sialoadenectomy was performed around the muscle and the branch of the facial nerve. The position of the sialolithiasis leads to the curving of the skin near granulation cells and sinus drainage (Fig. 1d) and the incision was closed layer by layer (Figs. 1e and 1f). All the

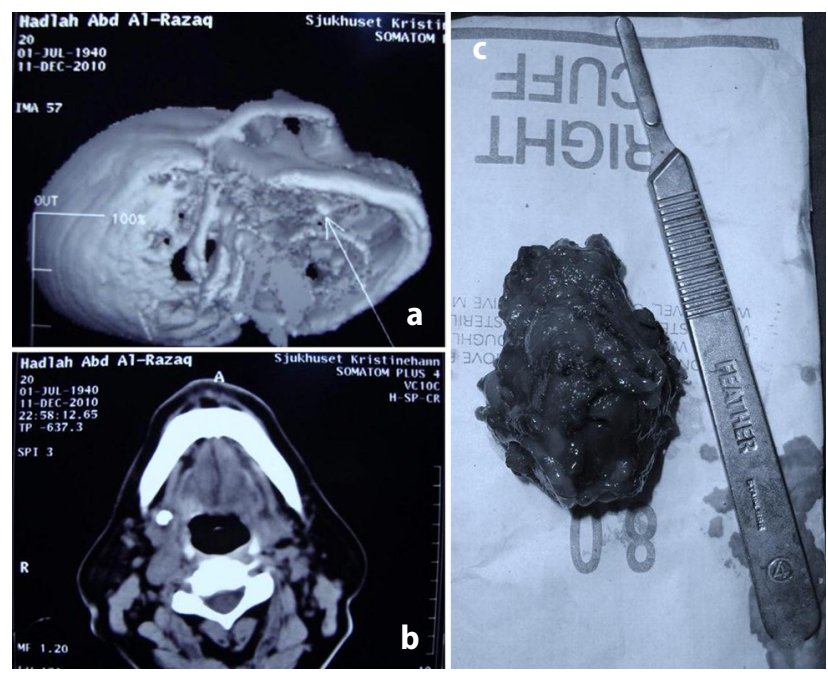

Fig 2. ( $a$ and $b$ ) The presence of the sialolith was confirmed on CT, with an opaque mass evident in the right submandibular region. (c) The patient underwent excision of the right submandibular gland.

patients underwent the same extra-oral surgical technique; affected side submandibular gland was removed along with the calculus and had uneventful healing without any postoperative intricacy.

\section{Discussion}

Sialolithiasis is a pathology manifested by impediment of ductal system by sialoliths (calculi). ${ }^{22}$ The growing dimensions 


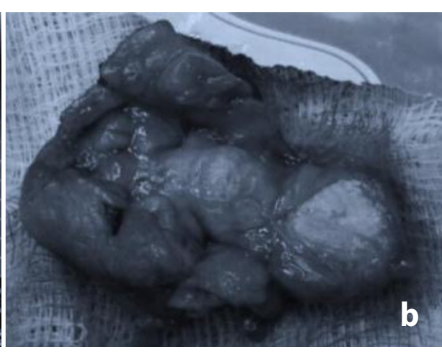

Fig 3. (a) A CT scan of the mandibular region showed the presence of a rounded radiopaque sialolith. (b) The sialolith was surgically removed under general anesthesia.

of calculi enhance the blockage of saliva release, causing infections and swollen glands. ${ }^{22}$ Complete obliteration causes painful enlargement. ${ }^{23}$ Prolonged impediment of the ductal system of the salivary glands causes consequential bereavement from saliva. ${ }^{24}$

The secretions of submandibular gland lead to increased levels of hydroxyapatite as well as phosphates enhanced viscosity, more mucous and escalated basicity. ${ }^{25}$ Therefore, it has more chances to develop calculus than all other salivary glands. This further leads to proclivity toward salt precipitation around the duct opening. ${ }^{25}$ The Wharton's duct is thin and traverses upward for its opening (shown in aforementioned image), and this anatomy tends to produce more hindrance in the saliva emancipation. ${ }^{26}$

The chief complaint of the patient includes ephemeral and discomforting pain swelling, during or after having food in the salivary glands which reduce within 2 or $3 \mathrm{~h}$ and most importantly curtailed saliva formation. ${ }^{26,27}$ Complications of sialolithiasis include presence of secondary infections, abscess formation, stenosed saliva ducts, mucocele development, chronic sclerosingsialadenitis (Kuttner's tumor) and chronic atrophic parenchymal layer of the gland. ${ }^{28,29}$ Bigger calculi are ovoid or long-drawn-out, firm, yellow and sponge like in appearance, which radiologically surface out as tooth-like structures. Similarly, the cases mentioned in this article have recurrent swelling pus discharge and pain in the gland. ${ }^{30}$ Observed subjects also have a fibrosis edema and palpable mass of sialoliths, felt by the examiner in the base of the mandible. ${ }^{31}$

Large stones are managed through surgical removal with or without the gland excision, whereas smaller ones require conservative treatment in the form of locales high-temperature application, acupressure, and saliva promoting drugs (sialagogues)..$^{32,33}$ Surgical removal of the damaged gland is a remedy for patients who have relapse of sialolithiasis and prove to be a gold standard cure in conditions when calculi are present within the nonfunctioning glands. However, eliminating the gland is mandatory in relapsing cases. ${ }^{34,35}$

Investigations helping in the diagnosis include radiographs, radiological sialography, USG, CT, MRI and endoscopy of the salivary glands. ${ }^{29}$ Though costly, tomographic investigation is the most meticulous non-surgical method for detecting the position, size of even the tiniest stones and the number of clustered sialoliths. ${ }^{17,29,36,37}$ After the successful removal of the submandibular gland and calculus, close followup is needed..$^{38}$ Submandibularadenectomy, sometimes, has a side effect on nerve (marginal mandibular) causing palsy (permanent or short-lived), though none of the subjects suffered from this condition. ${ }^{39}$

\section{Conclusion}

The study was highlighting the first line of treatment of sialolithiasis as adenectomy. The finding of the present study suggests that any gland having fibrotic, infectiously swelled, pus releasing, loss of function with a sialolith should undergo sialadenectomy.

\section{Conflict of Interest}

The authors reveal that they have no monetary clash of interest in connection to this work.

\section{References}

1. Gupta A, Rattan D, Gupta R. Giant sialoliths of submandibular gland duct: report of two cases with unusual shape. Contemp Clin Dent. 2013:4:78-80.

2. Blitzer A. Inflammatory and obstructive disorders of salivary glands. J Dent Res. 1987;66 Spec No: 675-679.

3. Williams MF. Sialolithiasis. Otolaryngol Clin North Am. 1999;32:819-834

4. Produl H, Seema E, Punnoose RS, Sanjay A. Deep and unusual sialolithiasis of submandibular duct and gland: a surgical dilemma. Indian J Otolaryngol Head Neck Surg. 2013:65:309-313.

5. Cawson RA, Odell EW. Essentials of Oral Pathology and Oral Medicine, 6th ed.; Edinburgh: Churchill Livingstone, 1988; pp. 239-240.

6. Taher AA. The incidence and composition of salivary stones (sialolithiasis) in Iran: analysis of 95 cases_a short report. Singapore Dent J. 1989;14:33-35.

7. Leung AK, Choi MC, Wagner GA. Multiple sialoliths and a sialolith of unusual size in the submandibular duct: a case report. Oral Surg Oral Med Oral Pathol Oral Radiol Endod. 1999:87:331-333.

8. Choi WS, Yoon HJ, Lee SH. Giant sialolithiasis of the submandibular gland: a case report. J Korean Assoc Oral Maxillofacial Surg. 2010;36:141-144.

9. Cho SH, Han JD, Kim JH, Lee SH, Jo JB, Kim CH, et al. Removal of submandibular calculi by surgical method and hydraulic power with curved needle: a case report. J Korean Assoc Oral Maxillofacial Surg. 2017:43:182-185.

10. Raksin SZ, Gould SM, Williams AC. Submandibular duct sialolith of unusual size and shape. J Oral Surg. 1975;33:142-145.

11. McKenna JP, Bostock DJ, McMenamin PG. Sialolithiasis. Am Fam Physician. 1987:36:119-125.

12. Work WP, Hecht DW. Inflammatory Disease of Major Salivary Glands. In Otolaryngology; Paparella MM, Shumrick DA, Eds.; W. B. Saunders: Philadelphia, 1980; Vol. 13, pp. 2235-2243.

13. Alyas F, Lewis K, Williams M, Moody AB, Wong KT, Ahuja AT, et al. Diseases of the submandibular gland as demonstrated using high resolution ultrasound. Br J Radiol. 2005;78:362-369.

14. Manjunath R, Burman R. Giant submandibular sialolith of remarkable size in the comma area of Wharton's duct: a case report. J Oral Maxillofacial Surg. 2009;67:1329-1332.

15. Tepan MG, Rohiwal RL. Multiple salivary calculi in Wharton's duct. J Laryngol Otol. 1985;99:1313-1314.

16. Abdel-Wahed N, Amer ME, Abo-Taleb NS. Assessment of the role of cone beam computed sialography in diagnosing salivary gland lesions. Imaging Sci Dent. 2013:43:17-23.

17. Oteri G, Procopio RM, Cicciu M. Giant salivary gland calculi (GSGC): report of two cases. Open Dent J. 2011:5:90-95.

18. Weissman JL. Imaging of the salivary gland. Semin Ultrasound CT MR. 1995; 16:546-568.

19. Juul ML, Wagner N. Objective and subjective outcome in 42 patients after treatment of sialolithiasis by transoral incision of Warthon's duct: a retrospective middle-term follow-up study. Eur Arch Otorhinolaryngol. 2014;271:3059-3066

20. Markiewicz MR, Margarone JE III, Tapia JL, Aguirre A. Sialolithiasis in a residual Wharton's duct after excision of a submandibular salivary gland. J Laryngol Otol. 2007;121:182-185.

21. Wallace E, Tauzin M, Hagan I. Management of giant sialoliths: review of the literature and preliminary experience with interventional sialendoscopy. Laryngoscope. 2010;120:1974-1978.

22. Levy DM, Remine WH, Devine KD. Salivary gland calculi. Pain, swelling associated with eating. JAMA. 1962;181:1115-1119. 
23. Antoniadis D, Mendonidou L, Papanayotou P, Trigonidis G. Clinical study of sialolithiasis. Findings from 100 cases. Hell Stomatol Chron. 1989;33:245-251.

24. Bodner L. Giant salivary gland calculi: diagnostic imaging and surgical management. Oral Surg Oral Med Oral Pathol Oral Radiol Endod. 2002;94:320-323.

25. Yousem DM, Kraut MA, Chalian AA. Major salivary gland imaging. Radiology. 2000;216:19

26. Bialek EJ, Jakubowski W, Zajkowski P, Szopinski KT, Osmolski A. US of the major salivary glands: anatomy and spatial relationships, pathologic conditions, and pitfalls. Radiographics. 2006;26:745-763.

27. Hasson O. Sialoendoscopy and sialography: strategies for assessment and treatment of salivary gland obstructions. J Oral Maxillofac Surg. 2007;65:300-304.

28. Drage NA, Brown JE, Escudier MP, McGurk M. Interventional radiology in the removal of salivary calculi. Radiology. 2000;214:139-142.

29. Madani G, Beale T. Inflammatory conditions of the salivary glands. Semin Ultrasound CT MR. 2006;27:440-451.

30. Kalia V, Kalra G, Kaur S, Kapoor R. CT scan as an essential tool in diagnosis of non-radiopaque sialoliths. J Maxillofac Oral Surg. 2015;14:240-244.

31. Ying $X$, Kang J, Zhang F, Dong H. Recurrent sialoliths after excision of the bilateral submandibular glands for sialolithiasis treatment: a case report. Exp Ther Med. 2016;11:335-337.
32. Graziani F, Vano M, Cei S, Mario G. Unusual asymptomatic giant sialolith of the submandibular gland: a clinical report. J Craniofac Surg. 2006;17: 549-552.

33. Hazarika P, Punnoose SE, Singh R, Arora S. Deep and unusual sialolithiasis of submandibular duct and gland: a surgical dilemma. Indian J Otolaryngol Head Neck Surg. 2013;65:309-313.

34. Fowell C, MacBean A. Giant salivary calculi of the submandibular gland. J Surg Case Rep. 2012;2012:6.

35. Iqbal A, Gupta AK, Natu SS, Gupta AK. Unusually large sialolith of Wharton's duct. Ann Maxillofac Surg. 2012;2:70-73.

36. UggaL, Ravanelli M, Pallottino AA, Farina D, Maroldi R. Diagnostic work-up in obstructive and inflammatory salivary gland disorders. Acta Otorhinolaryngol Ital. 2017;37:83-93.

37. Rzymska-Grala I, Stopa Z, Grala B, Gołębiowski M, Wanyura H, Zuchowska A, et al. Salivary gland calculi - contemporary methods of imaging. Pol J Radiol. 2010;75:25-37.

38. Arslan S, Vuralkan E, Çobanog lu B, Arslan A, Ural A. Giant sialolith of submandibular gland: report of a case. J Surg Case Rep. 2015;2015: pii. rjv043.

39. Siddiqui SJ. Sialolithiasis: an unusually large submandibular salivary stone. Br Dent J. 2002;193:88-99.

This work is licensed under a Creative Commons Attribution-NonCommercial 3.0 Unported License which allows users to read, copy, distribute and make derivative works for non-commercial purposes from the material, as long as the author of the original work is cited properly. 